\title{
A cross-sectional survey of prevalence and related factors for frail status among middle-aged and elderly people in Chinese communities
}

\section{Chao Sun}

Fourth Military Medical University

\section{Yue Hu}

Xinjiang Medical University

Jie Yang

Fourth Military Medical University

\section{Xing Li}

Fourth Military Medical University

\section{Cong Huo}

Fourth Military Medical University

\section{Xin Jia}

Fourth Military Medical University

\section{Rong Xu}

Fourth Military Medical University

\section{Liming Hou}

Fourth Military Medical University

Yunzhen Lei

Fourth Military Medical University

Xiaoming Wang ( $\nabla$ xmwang@fmmu.edu.cn)

Xijing Hospital, Fourth Military Medical University https://orcid.org/0000-0002-9671-6358

\section{Research article}

Keywords: Chinese, cystatin C, frailty, pre-frailty, hypertension, prevalence, related factors

Posted Date: August 27th, 2020

DOl: https://doi.org/10.21203/rs.3.rs-49204/v2

License: (1) (1) This work is licensed under a Creative Commons Attribution 4.0 International License.

Read Full License 


\section{Abstract}

Background: With the aggravation of social competition and work burden pressure, the health condition of the middle-aged and above population in China has declined significantly. Frailty can be used as a criterion for evaluating a person's unhealthy state. However, there is limited data on the prevalence and related factors of frail status in Chinese middle-aged and older people.The objective of this study was to explore the correlation between frail status, chronic diseases, abnormal physical examination indicators among middle-aged and older populations.

Methods: Participants were 9,985 community-dwelling adults over the age of 40 years living in China. Data were from the 2015 China Health and Retirement Longitudinal Survey which was a nationally representative sample and frailty phenotype was based on Fried frailty criteria. We analyzed the demographics of participants and multivariate-adjusted related factors for frail and pre-frail population.

Results: The overall prevalence of frailty and pre-frailty was 3.1\% (95\% Cl: $2.8,3.5)$ and $53.66 \%$ (95\% Cl: 52.7, 54.6) among the general Chinese population aged 40 years or older. Hypertension (OR: $1.8,95 \% \mathrm{Cl}$ : 1.3, 2.593), pain (OR: $1.8,95 \%$ Cl: $1.3,2.5$ ), and hip fracture (OR: $2.2,95 \% \mathrm{Cl}: 1.1,4.4$ ) were associated with prevalent frailty. Relative factors for frailty also included increased cystatin C (OR: 4.5, 95\% Cl: 3.0, 6.7) and glycated hemoglobin (OR: $1.2,95 \% \mathrm{Cl}: 1.1,1.4$ ), as well as decreased peak expiratory flow (OR: 0.993, 95\% Cl: 0.991, 0.994).

Conclusions: Fried-defined frailty and pre-frailty are highly prevalent in the Chinese population over 40 years older. Hypertension, pain, hip fracture, low education, and underweight are major related factors for frailty. The decrease in peak expiratory flow and the increase in cystatin $\mathrm{C}$ and glycated hemoglobin are good indicators for detecting frailty. Thus, frailty is an increasingly common condition and will become a major important health issue for people over middle age.

\section{Background}

With the rapid development of China's social modernization and population aging, the aggravation of social competition and work burden has led to the obvious decline in the healthy condition of the middleaged and above Chinese people. As an unhealthy status of individual body and mind, frailty has attracted more and more attention from researchers. There is a common agreement that frailty is a medical syndrome in which strength and physiological functions are reduced by multiple factors to increase individual vulnerability [1]. Fried phenotype of frailty is the most frequently used serve as a criterion for assessing a person's frail state in the literature [2]. The causes of frailty are multifaceted, including age, lower-income, polypharmacy, sarcopenia, depression, malnutrition, falls [3-13]. Several studies have also shown that some chronic diseases, such as hypertension, anemia, chronic obstructive pulmonary disease and diabetes are related to the occurrence of frailty [14-17].

China has the largest population base and the health of expenditure is a heavy economic burden for personal and societal cost is enormous [18]. Compared with developed countries, China's population has 
great regional differences in diet and living habits, unbalanced economic status and medical services, and the number of patients with chronic diseases continues to grow rapidly [19-21]. Therefore, the related factors and chronic disease characteristics of the frail population in China may be very different from those in Europe and the United States [22]. However, most of the study evidence comes from developed countries, and the research on frailty in China has just started [23]. Based on 2011 China Health and Retirement Longitudinal Survey (CHARLS) data, Wu and his colleagues found that the prevalence of frailty among the Chinese community population aged 60 and older was 7\% [24]. But their study did not include the middle-aged population, and did not calculate the prevalence of pre-frailty in our country. Some studies indicate that frailty and pre-frailty are identified in middle age (40 to 59 years old), which may have implications for prognosis and planned intervention, especially in individuals with multimorbidity [25]. The purpose of this study was to identify the prevalence of frailty and pre-frailty in middle-aged and elderly Chinese, and to explore related factors.

\section{Methods}

Data source and study design

In our study, we used the survey date from the 2015 CHARLS, which is a nationally representative longitudinal cohort study including community-dwelling mid-aged and elderly population collectively in China. It used a multistage stratified cluster sampling procedure to select the respondents and followed up every two years. A large-scale baseline survey was conducted from 2011 to 2012, covering all countylevel units in mainland China (excluding Tibet). The sample includes 150 counties/districts (spread across 28 provinces and regions) and 450 villages / urban communities with a total of 17,708 people. The survey gathered information about socioeconomic characteristics, living habits, health status, and other demographic messages by face-to-face interviews and also presented biomarkers, blood date, anthropometric and other physical measurements. As specific measurements and questions for the CHARLS differed from the Cardiovascular Health Study in which Fried theorized the frailty phenotype by analyzing the data, we made minor modifications based on data availability for the Chinese version. According to Fried's frailty criteria, our definition of frail status was assessed through five aspects: walking speed, grip strength, fatigue, physical activity and weight loss. Table 1 shows our definitions in detail.

Biomarker and follow-up questionnaire data

In CHARLS, a trained interviewer measured blood pressure and pulse 3 times on the participants' left arm with an electronic blood pressure monitor (Omron HEM-7200 Monitor). We first calculated the mean value of the 3 blood pressure and pulse readings for every participant. According to the value of blood pressure, the population of hypertension is divided into 5 levels (Table 5) [26].

The interviewer measured twice on each hand of the participants by using an electronic grip dynamometer (Yuejian WL-1000 mechanical dynamometer), and the average value of the dominant hand was calculated as the final grip strength to be included in the analysis. Similarly, the interviewer 
used a stopwatch to record the time at which the participant walked at a usual pace of 2.5 meters twice, taking the average time to calculate the pace. walking speed $=2.5(\mathrm{~m}) /$ time $(\mathrm{s})$. Interviewers measured and recorded participants' height, waist circumference and weight with stadiometer and scale.

Trained interviewers used the peak flow meter to conduct the peak expiratory flow (PEF) for three times. Participants opened their mouth and closed lips firmly around the outside of the mouthpiece, and then blew as hard and as fast as they can into the mouthpiece. We recorded the measurement readings and calculated the mean value.

According to answer these questions, such as "have you fallen down?" and "have you ever fractured hip", and "are you troubled with body pains?", participants were divided with "yes or no". The definition of chronic diseases was based on participates self-reported diagnosis by a doctor. The ethical review committee approved the protocol of study and all study participants obtained written informed consent.

Statistical analysis

In our study, sociodemographic characteristics, self-reported health status, physical tests, and other relevant information (a little of date were missing) were summarized for non-frail, pre-frail and frail participants. We provided reliable estimates of the prevalence of frailty status for both men and women in five age groups. The prevalence of frailty status among men and women is presented as percentages with a $95 \%$ confidence interval $(\mathrm{Cl})$. Quantitative data conforming to normal distribution and homogeneity of variance tests were expressed in mean values and standard deviation, and were compared by one-way analysis of variance. Qualitative data was expressed in numbers and percentages, and compared with the Chi-squared test.

We assessed the association between frailty status and risk factors with univariate and multivariable logistic regression models. The different frailty status of chronic diseases was calculated odds ratios (OR), $95 \% \mathrm{Cl}$, and P-value. All the important variables in the correlation analysis were included in the final model. We used SPSS 23.0 (IBM Corp., Armonk, NY, USA) software and Excel 2016 (Microsoft Corp., Redmond Washington, USA) to conduct statistical analyses, and the significance level was set at 0.05 (2 tail test).

\section{Results}

The baseline population was based on the second nationwide follow-up survey conducted in 2015, which included 16,730 people. After excluding individuals with unreliable physical tests and critical data missing, 9985 participants ( 4585 men and 5400 women) were included in the final analysis. General characteristics and partial related factors of the study population are summarized in Table 2, by grades of frailty and gender. In terms of frailty status, 4316, 5338, and 311 patients were classified as non-frail, pre-frail, and frail, respectively. 
Table 3 showed the overall prevalence of Fried frailty phenotype defined frailty and pre-frailty were $3.1 \%$ (95\% Cl: $2.8,3.5)$ and $53.7 \%(95 \% \mathrm{Cl}: 52.7,54.6)$ among the general Chinese population aged 40 years or older. In a subgroup analysis of the prevalence of frailty, women $(4.2 \%, 95 \% \mathrm{Cl}: 3.7,4.8)$ were higher than men $(1.8 \%, 95 \% \mathrm{Cl}: 1.4,2.2)$, rural areas $(3.3 \%, 95 \% \mathrm{Cl}: 2.9,3.7)$ were higher than Urban $(2.6 \%, 95 \% \mathrm{Cl}: 1.9$, $3.2)$, under weight $(10.9 \%, 95 \% \mathrm{Cl}: 8.5,13.3)$ was higher than normal weight $(1.6 \%, 95 \% \mathrm{Cl}: 1.3,2.0)$, and illiterate $(5.6 \%, 95 \% \mathrm{Cl}: 4.8,6.5)$ was higher than elementary school $(2.8 \%, 95 \% \mathrm{Cl}: 2.3,3.3)$.

The results of serum and physical measurements classified by frailty status are shown in the table 4 . The mean cystatin $C$ levels in the frail, pre-frail and non-frail groups were $1.0 \pm 0.5 \mathrm{mg} / \mathrm{L}, 0.9 \pm 0.3 \mathrm{mg} / \mathrm{L}$ and $0.8 \pm 0.2 \mathrm{mg} / \mathrm{L}$, respectively $(P<0.001)$. There was signifcant diference in systolic blood pressure according to frailty status (frail: $133.8 \pm 23.6 \mathrm{mmHg}$, pre-frail: $129.2 \pm 21.0 \mathrm{mmHg}$, non-frail: $127.9 \pm$ $19.1 \mathrm{mmHg}, P<0.001)$, however, diastolic blood pressure was lower in frail person $(73.7 \pm 11.8 \mathrm{mmHg})$ than pre-frail $(74.7 \pm 11.8 \mathrm{mmHg})$ or non-frail $(76.3 \pm 11.9 \mathrm{mmHg})(\mathrm{P}<0.001)$. The mean blood pressure of the different frailty status was in the normal range.

Table 5 shows the results of our unadjusted and fully adjusted logistic regression models of the overall population. In the univariate-unadjusted analyses, hypertension was more likely to develop frailty or prefrailty. The higher the blood pressure, the greater the risk of frailty (Grade 3 hypertension, OR: $2.75,95 \%$ Cl: $1.67,4.53 ; P<0.001$ ) and pre-frailty (Grade 3 hypertension, OR: $1.38,95 \% \mathrm{Cl}: 1.10,1.74 ; P=0.006$ ). Unadjusted analysis also showed that for every $1 \mathrm{mg} / \mathrm{L}$ increase in serum cystatin $\mathrm{C}$, the risk of frailty increased by more than 6.8 times (OR: $6.86,95 \% \mathrm{Cl}: 4.63,10.15 ; P<0.001)$. In multivariable-adjusted analyses, hypertension was still associated significantly with risk of frailty (OR: $1.82,95 \% \mathrm{Cl}: 1.27,2.59 ; P$ $<0.001$ ) and pre-frailty (OR: 1.16, 95\% Cl: 1.02, 1.32; $P=0.02$ ). Compared to normal blood pressure, person in grade 3 hypertension had a two-fold greater odds of frailty (OR: 2.14, 95\% Cl: 1.10, 4.17; $P=$ 0.024). Multivariate analysis showed that gender (OR: $0.52,95 \% \mathrm{Cl}: 0.47,0.59$; $\mathrm{P}<0.001$ ), pain (OR: 1.80, 95\% Cl: $1.31,2.46 ; P<0.001$ ), hip fracture (OR: $2.18,95 \% \mathrm{Cl}: 1.07,4.43 ; \mathrm{P}=0.032$ ), cystatin C ( OR: 4.50 , $95 \% \mathrm{Cl}: 3.01,6.74 ; P<0.001$ ), glycated hemoglobin (OR: 1.07, 95\% Cl: 1.07, 1.40; $P=0.003$ ), and peak expiratory flow (OR: $0.993,95 \% \mathrm{Cl}: 0.991,0.994 ; P<0.001)$ were also relative factors with frailty.

\section{Discussion}

Our estimated prevalence of frailty was $3.1 \%$ among the Chinese population aged 40 years or older, which is very similar to the reported by Hanlon and colleagues that around $3 \%$ of people aged 37 to 73 were considered frail in the United Kingdom[25]. To our knowledge, our research is the first survey reporting the middle-aged of frailty in China, showing prevalence of $2.4 \%$ aged $40-49$ and $3.6 \%$ aged $50-59$, which was lower than the middle-age of frailty in community-dwelling Europeans was $4.1 \%$ and was much lower than reported the prevalence of frailty was $7.6 \%$ and $13.4 \%$ among adult white Americans aged $35-44$ and $45-54$, respectively[27,28]. It can be seen that frailty not only has a higher incidence in the elderly, but also occurs in the middle-aged population. Research has shown that the frailty of the body may lead to disability in the future, but in the early stages of intervention, this outcome can be changed [29]. So many studies published about the prevalence of pre-frailty, such as United States (45.0\%), UK(38.0\%), Japan 
(48.1\%), Israel (57.4\%), similarly, the proportion of pre-frail Chinese in our research was also very high $(53.7 \%)[3,25,30,31]$.

These distinctions might be mainly due to differences in socioeconomic background, ethnicity, and lifestyle of people living in different countries and regions [31]. In addition, using different frailty measurement tools for the same population, such as Fried frailty phenotype, Frail index, and FRAIL scales, would have an impact on the outcome of the prevalence of pre-frailty and frailty [32].

We found in the multivariate analysis, people who reported hypertension had 1.8 times the risk of developing frailty compared to those who did not, and the risk of pre-frailty is 1.1 times. Even after adjusting for potential confounding factors, the higher the blood pressure level, the greater the chance of suffering from frailty. Also in previous studies, there was a strong association between hypertension and frailty, and it was confirmed that patients with frailty and pre-frailty had significant subclinical vascular and cardiac changes $[33,34]$. However, the conclusions of blood pressure and frailty research are divergent, and some authors have shown that measured mean blood pressure was lower in frail compared to non-frail individuals [35]. They thought low blood pressure may reduce blood perfusion and oxygenation of vital organs, resulting in damage, loss of function, and a frail state [36]. This difference in blood pressure was explained that high blood pressure is harmful to people's health, whether the population was frail or not, it was possible to use antihypertensive treatment. Studies have shown that hypertension can cause frailty, and as a variable, frailty may affect changes in blood pressure. These findings raise questions about statistical differences regarding the blood pressure values in different frail states of the population require additional evidence.

We observed there was a strong association between frail status and elevated serum cystatin C. Multivariate analysis showed that participants with higher cystatin $\mathrm{C}$ had 4.5 -fold increased risk of frailty and 2.4-fold increased risk of pre-frailty. Hart et al found that higher serum cystatin $\mathrm{C}$ was associated with increased risks of progression of frailty status and death [37]. Cystatin $\mathrm{C}$ is a low molecular weight protein with a stable productivity and can be freely filtered by the glomeruli [38], which is more appropriate for the group who are susceptible to be frail because it seems to be less affected by muscle mass or dietary protein intake[39]. Our findings, like those of other studies, suggest that cystatin C is more sensitive to the detection of frailty than other blood biomarkers such as creatinine [40]. These results may partially explain the increased sensitivity of cystatin $C$ in identifying older people with less muscle. Because cystatin $\mathrm{C}$ was not affected by muscle mass or dietary protein intake, it was more reflective of changes in physical performance than other kidney function markers such as creatinine [39]. Inflammation may play a role as a potential mechanism linking cystatin $C$ to frailty [41]. Due to the limitations of current frailty knowledge, the mechanism linking higher cystatin $\mathrm{C}$ to frailty was unclear and future research is needed to further explore this phenomenon [37].

In this study, we also identified other relative factors associated with frailty and pre-frailty in the Chinese community population. Gender, education level, BMI, glycated hemoglobin (HbA1C), PEF and pain are major relative factors for frailty. The prevalence of frailty and pre-frailty in women was higher than in 
men, which is consistent with previously published studies [5,42]. We also found that higher education has a strong protective effect on the prevalence of frailty. The education level of individuals is one of the important indicators to measure their socioeconomic status [43]. Lower economic income is associated with an increased risk of frailty $[5,28]$. The prevalence of frailty increased with low BMI. Our findings corroborate the views that a lower BMI may indicate insufficient reserve capacity and weight loss, which was a key factor in the formation of frailty [44]. Underweight may be due to chronic illness or malnutrition and sarcopenia, which were also associated with increased risk of frailty [45].

Our study indicated that the decrease in PEF and the increase in $\mathrm{HbA1C}$ may be good indicators for detecting frailty. The result is similar to previous studies on respiratory function and frailty, in which PEF values were lower in frail elderly people than in non-frail people [46]. This mechanism may be related to decreased function of the respiratory muscles or chronic inflammation of the lungs that led to a decline in the body's energy reserves and physical strength [47]. Similarly, our results showed that for every 1 percent increased in serum HbA1C, the risk of frailty had higher odds. Several studies had shown that diabetes and $\mathrm{HbA} 1 \mathrm{C}$ were risk factors for frailty and patients with poor blood sugar control had a higher risk of developing frailty $[17,48]$. Thus, frailty is an increasingly common condition and will become an increasingly important health issue for people over middle age. Next, how to prevent the frailty of the population should become one of the major medical concerns.

Our study has several limitations. First, the chronic diseases and symptoms were self-reported, therefore, it would cause reporting bias and recall bias. Second, because the biological and clinical characteristics of middle-aged people were different from those of the elderly, the concept of frailty, especially the definition of Fried frailty phenotype, when applied to non-elderly, the applicable conditions and principles of definition here need to be further studied in the future. Third, due to the survey of CHARLS was only included community-dwellers, not including those in hospitals and nursing homes, and some people who may have serious illnesses that cannot be interviewed and measured were excluded. In addition, the proportion of the elderly population in the surveyed population was low (age $\geq 60$ years had $48.1 \%$ and age $\geq 80$ years had $4.1 \%$ ), while the elderly population was a high-risk group with frailty. Therefore, the actual incidence of frailty may be underestimated. Fourth, We found that in the above studies on the frailty and pre-frailty, due to the large or minor modifications to the Fried frailty phenotype or other frailty assessment instruments in order to accommodate the data, would have a significant impact on the estimation of frailty and pre-frailty population, and we should be cautious about the publication of this conclusion. The last, since this research was a retrospective cross-sectional study, there was insufficient clinical evidence to assess the role of chronic diseases in different stages of the frailty process, and we could not understand the causal and temporal relationship between frailty and chronic diseases. The next step is to conduct prospective cohort studies and randomized controlled trials to serve clinical guidelines.

\section{Abbreviations}

BMI: Body mass index; CHARLS: China Health and Retirement Longitudinal Study; Cl: confidence interval; DBP: diastolic blood pressure; HbA1C: glycated hemoglobin; OR: odds ratios; SBP: systolic blood 
pressure; PEF: peak expiratory flow;

\section{Declarations}

\section{Ethics approval and consent to participate}

The biomarker sample collection study protocol was approved by the ethical review committee (institutional review board) of Peking University (IRB 00001052-11014). Written informed consent was obtained from all study participants.

\section{Availability of data and materials}

All data used in the study and questionnaire can be accessed through after registering publicly online website (http://charls.pku.edu.cn/en).

\section{Consent for publication}

Not applicable.

\section{Competing interests}

The authors declare that they have no competing interests.

\section{Funding}

Our study was supported by the National Natural Science Foundation of China (No.81870184), and National Key R\&D Program of China (SQ2018YFC200004-05).

The funder played no role in study design, data collection, and analysis, the decision to publish, or preparation of the manuscript.

\section{Authors' contributions}

The individual contributions of each author are as follows: CS, YH, JY, LH, and XW conceived and designed the study. XW supervised the study. $\mathrm{XL}, \mathrm{CH}, \mathrm{JX}$ and $\mathrm{RX}$ did the statistical analysis. CS, YH区JX and $\mathrm{YL}$ contributed to data collection, analysis, and interpretation. $\mathrm{CS}, \mathrm{YH}$ and $\mathrm{XW}$ drafted the report. All authors have read and approved the manuscript.

\section{Acknowledgements}

We thank the China Health and Retirement Longitudinal Study (CHARLS) team, who collected data and assisted with data access.

\section{References}


1. Morley JE, Vellas B, van Kan GA, et al. Frailty consensus: a call to action. J Am Med Dir Assoc. 2013;14:392-397.

2. Fried LP, Tangen $C M$, Walston J, et al. Frailty in older adults: evidence for a phenotype. J Gerontol A Biol Sci Med Sci. 2001;56:146-156.

3. Bandeen-Roche K, Seplaki CL, Huang J, et al. Frailty in older adults: a nationally representative profile in the United States. J Gerontol A Biol Sci Med Sci. 2015;70:1427-1434.

4. Haider S, Grabovac I, Dorner TE. Effects of physical activity interventions in frail and prefrail community-dwelling people on frailty status, muscle strength, physical performance and muscle mass-a narrative review. Wien Klin Wochenschr. 2019;131:244-254.

5. Biritwum RB, Minicuci N, Yawson AE, et al. Prevalence of and factors associated with frailty and disability in older adults from China, Ghana, India, Mexico, Russia and South Africa. Maturitas. 2016;91:8-18.

6. Prince CS, Noren Hooten N, Mode NA, et al. Frailty in middle age is associated with frailty status and race-specific changes to the transcriptome. Aging (Albany NY). 2019;11:5518-5534.

7. Yuki A, Otsuka $R$, Tange $C$, et al. Polypharmacy is associated with frailty in Japanese communitydwelling older adults. Geriatr Gerontol Int. 2018;18:1497-1500.

8. Horibe $Y$, Ueda T, Watanabe $Y$, et al. A 2-year longitudinal study of the relationship between masticatory function and progression to frailty or pre-frailty among community-dwelling Japanese aged 65 and older. J Oral Rehabil. 2018;45:864-870.

9. Reijnierse EM, Trappenburg MC, Blauw GJ, et al. Common ground? The concordance of sarcopenia and frailty definitions. J Am Med Dir Assoc. 2016;17:371.e377-312.

10. Soysal P, Veronese N, Thompson T, et al. Relationship between depression and frailty in older adults: a systematic review and meta-analysis. Ageing Res Rev. 2017;36:78-87.

11. Wei K, Nyunt MS, Gao Q, et al. Association of frailty and malnutrition with long-term functional and mortality outcomes among community-dwelling older adults: results from the Singapore Longitudinal Aging Study 1. JAMA Netw Open. 2018;1:e180650.

12. Wei $\mathrm{K}$, Nyunt MSZ, Gao Q, et al. Frailty and malnutrition: related and distinct syndrome prevalence and association among community-dwelling older adults: Singapore Longitudinal Ageing Studies. J Am Med Dir Assoc. 2017;18:1019-1028.

13. Lan X, Li H, Wang Z, Chen Y. Frailty as a predictor of future falls in hospitalized patients: A systematic review and meta-analysis. Geriatr Nurs. 2020;41(2):69-74.

14. Vetrano DL, Palmer KM, Galluzzo L, et al. Hypertension and frailty: a systematic review and metaanalysis. BMJ Open. 2018;8:e024406.

15. Palmer K, Vetrano DL, Marengoni A, et al. The Relationship between Anaemia and Frailty: A Systematic Review and Meta-Analysis of Observational Studies. J Nutr Health Aging. 2018;22(8):965-974. 
16. Marengoni A, Vetrano DL, Manes-Gravina E, Bernabei R, Onder G, Palmer K. The Relationship Between COPD and Frailty: A Systematic Review and Meta-Analysis of Observational Studies. Chest. 2018;154(1):21-40.

17. Assar ME, Laosa O, Rodriguez Manas L. Diabetes and frailty. Curr Opin Clin Nutr Metab Care. 2019;22:52-57.

18. Dou G, Wang Q, Ying X. Reducing the medical economic burden of health insurance in China: Achievements and challenges. Biosci Trends.2018;12(3):215-219.

19. Wang FS, Fan JG, Zhang Z, Gao B, Wang HY. The global burden of liver disease: the major impact of China. Hepatology. 2014;60(6):2099-2108.

20. Zhao D, Liu J, Wang M, Zhang X, Zhou M. Epidemiology of cardiovascular disease in China: current features and implications. Nat Rev Cardiol. 2019;16(4):203-212.

21. Zhang L, Wang F, Wang L, et al. Prevalence of chronic kidney disease in China: a cross-sectional survey. Lancet. 2012;379(9818):815-822.

22. Shi GP, Ma T, Zhu YS, et al. Frailty phenotype, frailty index and risk of mortality in Chinese elderly population- Rugao longevity and ageing study. Arch Gerontol Geriatr. 2019;80:115-119.

23. Li J, Vellas B, Dong B, et al. Frailty in China. J Am Med Dir Assoc. 2015;16:711-712.

24. Wu C, Smit E, Xue QL, et al. Prevalence and correlates of frailty among community-dwelling Chinese older adults: the China Health and Retirement Longitudinal Study. J Gerontol A Biol Sci Med Sci. 2017;73:102-108.

25. Hanlon P, Nicholl BI, Jani BD, et al. Frailty and pre-frailty in middle-aged and older adults and its association with multimorbidity and mortality: a prospective analysis of 493737 UK Biobank participants. The Lancet Public Health. 2018;3:e323-e332.

26. Lisheng L, Chinese Guidelines for the Management of Hypertension, Chinese Hypertension League, et al. 2018 Chinese guidelines for the management of hypertension. Chinese Journal of Cardiovascular Medicine. 2019;24:24-56.

27. Santos-Eggimann B, Cuenoud P, Spagnoli J, et al. Prevalence of frailty in middle-aged and older community-dwelling Europeans living in 10 countries. J Gerontol A Biol Sci Med Sci. 2009;64:675681.

28. Griffin FR, Mode NA, Ejiogu N, et al. Frailty in a racially and socioeconomically diverse sample of middle-aged Americans in Baltimore. PLoS One. 2018;13:1-12.

29. Gill TM, Gahbauer EA, Allore HG, et al. Transitions between frailty states among community-living older persons. Arch Intern Med. 2006;166:418-423.

30. Kojima G, Iliffe S, Taniguchi Y, et al. Prevalence of frailty in Japan: a systematic review and metaanalysis. J Epidemiol. 2017;27:347-353.

31. Buch A, Keinan-Boker L, Berner Y, et al. Estimated frailty prevalence among Israeli elderly - results from a cross sectional national survey. Isr J Health Policy Res. 2018;7:18. 
32. He B, Ma Y, Wang $\mathrm{C}$, et al. Prevalence and risk factors for frailty among community-dwelling older people in China: a systematic review and meta-analysis. J Nutr Health Aging. 2019;23:442-450.

33. Kang MG, Kim SW, Yoon SJ, et al. Association between frailty and hypertension prevalence, treatment, and control in the elderly Korean population. Scientific reports. 2017;7:7542.

34. Veronese N, Cereda E, Stubbs B, et al. Risk of cardiovascular disease morbidity and mortality in frail and pre-frail older adults: Results from a meta-analysis and exploratory meta-regression analysis. Ageing Res Rev. 2017;35:63-73.

35. Anker D, Santos-Eggimann B, Zwahlen M, et al. Blood pressure in relation to frailty in older adults: A population-based study. J Clin Hypertens (Greenwich). 2019;21(12):1895-1904.

36. Muller M, Smulders YM, de Leeuw PW, Stehouwer CD. Treatment of hypertension in the oldest old: a critical role for frailty? Hypertension. 2014;63(3):433-441.

37. Hart A, Paudel ML, Taylor BC, et al. Cystatin C and frailty in older men. J Am Geriatr Soc. 2013;61(9):1530-1536.

38. Baxmann AC, Ahmed MS, Marques NC, et al. Influence of muscle mass and physical activity on serum and urinary creatinine and serum cystatin C. Clin J Am Soc Nephrol. 2008;3(2):348-354.

39. Canney M, Sexton DJ, O'Connell MDL, Kenny RA, Little MA, O'Seaghdha CM. Kidney Function Estimated From Cystatin C, But Not Creatinine, Is Related to Objective Tests of Physical Performance in Community-Dwelling Older Adults. J Gerontol A Biol Sci Med Sci. 2017;72(11):1554-1560. doi:10.1093/gerona/glx039

40. Hart A, Blackwell TL, Paudel ML, et al. Cystatin C and the Risk of Frailty and Mortality in Older Men. J Gerontol A Biol Sci Med Sci. 2017;72(7):965-970.

41. Stevens $\mathrm{LA}$, Schmid $\mathrm{CH}$, Greene T, et al. Factors other than glomerular filtration rate affect serum cystatin C levels. Kidney Int. 2009;75(6):652-660.

42. Zhang Q, Guo H, Gu H, et al. Gender-associated factors for frailty and their impact on hospitalization and mortality among community-dwelling older adults: a cross-sectional population-based study. PeerJ. 2018;6:e4326.

43. Wang $\mathrm{C}, \mathrm{Xu} \mathrm{J}$, Yang $\mathrm{L}$, et al. Prevalence and risk factors of chronic obstructive pulmonary disease in China (the China Pulmonary Health [CPH] study): a national cross-sectional study. The Lancet. 2018;391:1706-1717.

44. Liao Q, Zheng Z, Xiu S, et al. Waist circumference is a better predictor of risk for frailty than BMI in the community-dwelling elderly in Beijing. Aging Clin Exp Res. 2018;30:1319-1325.

45. Rolland Y, Abellan van Kan G, Gillette-Guyonnet S, et al. Cachexia versus sarcopenia. Curr Opin Clin Nutr Metab Care. 2011;14:15-21.

46. Marengoni A, Vetrano DL, Manes-Gravina E, et al. The relationship between COPD and frailty: a systematic review and meta-analysis of observational studies. Chest. 2018;154:21-40.

47. Trevisan C, Rizzuto D, Maggi S, Sergi G, Welmer AK, Vetrano DL. Cross-Sectional and Longitudinal Associations between Peak Expiratory Flow and Frailty in Older Adults. J Clin Med. 2019;8(11):1901. 
48. Yanase T, Yanagita I, Muta K, et al. Frailty in elderly diabetes patients. Endocr J. 2018;65:1-11.

\section{Tables}

Table 1.Definition of frailty criteria for middle-aged and old people in China ${ }^{\mathrm{a}}$

\begin{tabular}{|c|c|c|}
\hline Criteria & \multicolumn{2}{|l|}{ Definition } \\
\hline \multirow{3}{*}{$\begin{array}{l}\text { Walking speed } \\
\text { b }\end{array}$} & Men: & Women: \\
\hline & height $\leq 173 \mathrm{~cm}$, time $\geq 3.85 \mathrm{~s}$; & height $\leq 159 \mathrm{~cm}$, time $\geq 3.85 \mathrm{~s}$; \\
\hline & height $>173 \mathrm{~cm}$, time $\geq 3.29 \mathrm{~s}$. & height $>159 \mathrm{~cm}$, time $\geq 3.29 \mathrm{~s}$. \\
\hline \multirow[t]{5}{*}{ Grip strength } & Men: & Women: \\
\hline & $\mathrm{BMI} \leq 24 \mathrm{~kg} / \mathrm{m}^{2}, \mathrm{GS} \leq 29 \mathrm{~kg}$ & $\mathrm{BMI} \leq 23 \mathrm{~kg} / \mathrm{m}^{2}, \mathrm{GS} \leq 17 \mathrm{~kg}$ \\
\hline & BMI $24.1 \sim 26.0 \mathrm{~kg} / \mathrm{m}^{2}$, GS $\leq 30 \mathrm{~kg}$; & BMI $23.1 \sim 26.0 \mathrm{~kg} / \mathrm{m}^{2}, \mathrm{GS} \leq 17.3 \mathrm{~kg}$ \\
\hline & BMI $26.1 \sim 28.0 \mathrm{~kg} / \mathrm{m}^{2}, \mathrm{GS} \leq 30 \mathrm{~kg}$ & BMI $26.1 \sim 29.0 \mathrm{~kg} / \mathrm{m}^{2}, \mathrm{GS} \leq 18 \mathrm{~kg}$ \\
\hline & BMI $>28 \mathrm{~kg} / \mathrm{m}^{2}, \mathrm{GS} \leq 32 \mathrm{~kg}$. & $\mathrm{BMI} \geq 29.0 \mathrm{~kg} / \mathrm{m}^{2}, \mathrm{GS} \leq 21 \mathrm{~kg}$ \\
\hline $\begin{array}{l}\text { Physical } \\
\text { activity }\end{array}$ & \multicolumn{2}{|c|}{ Do less than ten minutes of moderate or hard intensity physical activity or walking time less than 30 minutes a day during a usual week. } \\
\hline Weight loss & \multicolumn{2}{|c|}{ Measured weight in 2015 lost more than 4.5 kilograms or at least $5 \%$ weight loss within two years } \\
\hline Exhaustion & \multicolumn{2}{|c|}{$\begin{array}{l}\text { In the last week, there was a period of time (more than a day) that I often felt unable to move on, or felt that everything I did needed hard } \\
\text { work. }\end{array}$} \\
\hline
\end{tabular}

Abbreviations: BMI, body mass index; GS, grip strength;

${ }^{a}$ Note: Participants met 3 or more of the above 5 criteria were defined as frail, met 1 or 2 criteria were defined as pre-frail, and met none of the frailty criteria were defined as not frail or robust.

${ }^{\mathrm{b}}$ The participants' average walking time of 2.5 meters was measured twice, stratified by sex and height.

Table 2. Demographics of the general Chinese adult population aged 40 years or older in $2015^{\text {a }}$ 


\begin{tabular}{|c|c|c|c|c|c|c|c|c|c|c|}
\hline & men & & & & & women & & & & \\
\hline & $\begin{array}{l}\text { Total } \\
(\mathrm{n}=4585)\end{array}$ & $\begin{array}{l}\text { Not frail } \\
(n=2540)\end{array}$ & $\begin{array}{l}\text { Pre-frail } \\
(n=1962)\end{array}$ & $\begin{array}{l}\text { Frail } \\
(\mathrm{n}=83)\end{array}$ & $P$-value & $\begin{array}{l}\text { Total } \\
(\mathrm{n}=5400)\end{array}$ & $\begin{array}{l}\text { Not frail } \\
(n=1776)\end{array}$ & $\begin{array}{l}\text { Pre-frail } \\
(\mathrm{n}=3396)\end{array}$ & $\begin{array}{l}\text { Frail } \\
(n=228)\end{array}$ & $P$-value \\
\hline Proportion of participants (\%) & $100 \%$ & $55.4 \%$ & $42.8 \%$ & $1.8 \%$ & & $100 \%$ & $32.9 \%$ & $62.9 \%$ & $4.2 \%$ & \\
\hline Age (years) & & & & & 0.337 & & & & & 0.007 \\
\hline $40-49$ & $857(18.7 \%)$ & $445(17.5 \%)$ & $399(20.3 \%)$ & $\begin{array}{l}13 \\
(15.7 \%)\end{array}$ & & $\begin{array}{l}1085 \\
(20.1 \%)\end{array}$ & $380(21.4 \%)$ & $672(19.8 \%)$ & $33(14.5 \%)$ & \\
\hline $50-59$ & $\begin{array}{l}1485 \\
(32.4 \%)\end{array}$ & $841(33.1 \%)$ & $613(31.2 \%)$ & $\begin{array}{l}31 \\
(37.4 \%)\end{array}$ & & $\begin{array}{l}1757 \\
(32.5 \%)\end{array}$ & $607(34.2 \%)$ & $\begin{array}{l}1064 \\
(31.3 \%)\end{array}$ & $86(37.7 \%)$ & \\
\hline $60-69$ & $\begin{array}{l}1390 \\
(30.3 \%)\end{array}$ & $786(30.9 \%)$ & $583(29.7 \%)$ & $\begin{array}{l}21 \\
(25.3 \%)\end{array}$ & & $\begin{array}{l}1621 \\
(30.0 \%)\end{array}$ & $497(28.0 \%)$ & $\begin{array}{l}1052 \\
(31.0 \%)\end{array}$ & $72(31.6 \%)$ & \\
\hline $70-79$ & $650(14.2 \%)$ & $351(13.8 \%)$ & $288(14.7 \%)$ & $\begin{array}{l}11 \\
(13.3 \%)\end{array}$ & & $730(13.5 \%)$ & $225(12.7 \%)$ & $471(13.9 \%)$ & $34(14.9 \%)$ & \\
\hline$\geqq 80$ & $203(4.4 \%)$ & $117(4.6 \%)$ & $79(4.0 \%)$ & $7(8.4 \%)$ & & $207(3.8 \%)$ & $67(3.8 \%)$ & $137(4.0 \%)$ & $3(1.3 \%)$ & \\
\hline Education level & & & & & $\begin{array}{l}< \\
0.001\end{array}$ & & & & & $\begin{array}{l}< \\
0.001\end{array}$ \\
\hline No formal education (illiterate) & $595(13.0 \%)$ & $241(9.5 \%)$ & $328(16.7 \%)$ & $\begin{array}{l}26 \\
(31.3 \%)\end{array}$ & & $\begin{array}{l}2137 \\
(39.6 \%)\end{array}$ & $573(32.3 \%)$ & $\begin{array}{l}1436 \\
(42.3 \%)\end{array}$ & $\begin{array}{l}128 \\
(56.1 \%)\end{array}$ & \\
\hline Elementary school & $\begin{array}{l}2187 \\
(47.7 \%)\end{array}$ & $\begin{array}{l}1142 \\
(45.0 \%)\end{array}$ & $\begin{array}{l}1009 \\
(51.4 \%)\end{array}$ & $\begin{array}{l}36 \\
(43.4 \%)\end{array}$ & & $\begin{array}{l}2139 \\
(39.6 \%)\end{array}$ & $725(40.8 \%)$ & $\begin{array}{l}1329 \\
(39.1 \%)\end{array}$ & $85(37.3 \%)$ & \\
\hline Middle and high school & $\begin{array}{l}1688 \\
(36.8 \%)\end{array}$ & $\begin{array}{l}1097 \\
(43.2 \%)\end{array}$ & $570(29.1 \%)$ & $\begin{array}{l}21 \\
(25.3 \%)\end{array}$ & & $\begin{array}{l}1079 \\
(20.0 \%)\end{array}$ & $460(25.9 \%)$ & $605(17.8 \%)$ & $14(6.1 \%)$ & \\
\hline College degree and higher & $106(2.3 \%)$ & $57(2.2 \%)$ & $49(2.5 \%)$ & $0(0 \%)$ & & $39(0.7 \%)$ & $17(1.0 \%)$ & $22(0.7 \%)$ & $0(0 \%)$ & \\
\hline Marital status & & & & & $\begin{array}{l}< \\
0.001\end{array}$ & & & & & $\begin{array}{l}< \\
0.001\end{array}$ \\
\hline Married and cohabitated & $\begin{array}{l}3937 \\
(85.9 \%)\end{array}$ & $\begin{array}{l}2249 \\
(88.5 \%)\end{array}$ & $\begin{array}{l}1625 \\
(82.8 \%)\end{array}$ & $\begin{array}{l}63 \\
(75.9 \%)\end{array}$ & & $4219 \square 78.1 \% \square$ & $\begin{array}{l}1475 \\
(83.1 \%)\end{array}$ & $\begin{array}{l}2597 \\
(76.5 \%)\end{array}$ & $\begin{array}{l}147 \\
(64.5 \%)\end{array}$ & \\
\hline $\begin{array}{l}\text { Divorce, separated and Never } \\
\text { married }\end{array}$ & $265(5.8 \%)$ & $143(5.6 \%)$ & $118(6.0 \%)$ & $4(4.8 \%)$ & & $289(5.4 \%)$ & $113(6.4 \%)$ & $169(5.0 \%)$ & $7(3.1 \%)$ & \\
\hline Widowed & $382(8.3 \%)$ & $148(5.8 \%)$ & $218(11.1 \%)$ & $\begin{array}{l}16 \\
(19.3 \%)\end{array}$ & & $892 \square 16.5 \% \square$ & $188(10.6 \%)$ & $630(18.6 \%)$ & $74(32.5 \%)$ & \\
\hline Current residence & & & & & 0.977 & & & & & 0.102 \\
\hline Urban & $\begin{array}{l}1001 \\
(21.8 \%)\end{array}$ & $557(21.9 \%)$ & $426(21.7 \%)$ & $\begin{array}{l}18 \\
(21.7 \%)\end{array}$ & & $\begin{array}{l}1213 \\
(22.5 \%)\end{array}$ & $415(23.4 \%)$ & $759(22.4 \%)$ & $39(17.1 \%)$ & \\
\hline Rural & $\begin{array}{l}3574 \\
(78.0 \%)\end{array}$ & $\begin{array}{l}1975 \\
(77.8 \%)\end{array}$ & $\begin{array}{l}1534 \\
(78.2 \%)\end{array}$ & $\begin{array}{l}65 \\
(78.3 \%)\end{array}$ & & $\begin{array}{l}4167 \\
(77.2 \%)\end{array}$ & $\begin{array}{l}1356 \\
(76.4 \%)\end{array}$ & $\begin{array}{l}2623 \\
(77.2 \%)\end{array}$ & $\begin{array}{l}188 \\
(82.5 \%)\end{array}$ & \\
\hline Alcohol consumption ${ }^{\mathrm{b}}$ & & & & & $\begin{array}{l}< \\
0.001\end{array}$ & & & & & 0.060 \\
\hline Drink more than once a month & $\begin{array}{l}2065 \\
(45.0 \%)\end{array}$ & $\begin{array}{l}1237 \\
(48.7 \%)\end{array}$ & $801(40.8 \%)$ & $\begin{array}{l}27 \\
(32.5 \%)\end{array}$ & & $424(7.9 \%)$ & $147(8.3 \%)$ & $257(7.6 \%)$ & $20(8.8 \%)$ & \\
\hline Drink but less than once a month & $462(10.1 \%)$ & $287(11.3 \%)$ & $174(8.9 \%)$ & $1(1.2 \%)$ & & $351(6.5 \%)$ & $135(7.6 \%)$ & $208(6.1 \%)$ & $8(3.5 \%)$ & \\
\hline None of these & $\begin{array}{l}2052 \\
(44.8 \%)\end{array}$ & $\begin{array}{l}1013 \\
(39.9 \%)\end{array}$ & $984(50.2 \%)$ & $\begin{array}{l}55 \\
(66.3 \%)\end{array}$ & & $\begin{array}{l}4621 \\
(85.6 \%)\end{array}$ & $\begin{array}{l}1491 \\
(84.0 \%)\end{array}$ & $\begin{array}{l}2930 \\
(86.3 \%)\end{array}$ & $\begin{array}{l}200 \\
(87.7 \%)\end{array}$ & \\
\hline Smoking history ${ }^{\mathrm{c}}$ & & & & & 0.075 & & & & & 0.022 \\
\hline Current smoker & $\begin{array}{l}2411 \\
(52.6 \%)\end{array}$ & $\begin{array}{l}1380 \\
(54.3 \%)\end{array}$ & $990(50.5 \%)$ & $\begin{array}{l}41 \\
(49.4 \%)\end{array}$ & & $283(5.2 \%)$ & $80(4.5 \%)$ & $189(5.6 \%)$ & $14(6.1 \%)$ & \\
\hline Former smoker & $\begin{array}{l}1192 \\
(26.0 \%)\end{array}$ & $631(24.8 \%)$ & $535(27.3 \%)$ & $\begin{array}{l}26 \\
(31.3 \%)\end{array}$ & & $152(2.8 \%)$ & $38(2.1 \%)$ & $102(3.0 \%)$ & $12(5.3 \%)$ & \\
\hline Never smoker & $978(21.3 \%)$ & $528(20.8 \%)$ & $434(22.1 \%)$ & $\begin{array}{l}16 \\
(19.3 \%)\end{array}$ & & $\begin{array}{l}4963 \\
(91.9 \%)\end{array}$ & $\begin{array}{l}1656 \\
(93.2 \%)\end{array}$ & $\begin{array}{l}3105 \\
(91.4 \%)\end{array}$ & $\begin{array}{l}202 \\
(88.6 \%)\end{array}$ & \\
\hline $\begin{array}{l}\text { Body mass index } \\
\left(\mathrm{kg} / \mathrm{m}^{2}\right)^{d}\end{array}$ & & & & & $\begin{array}{l}< \\
0.001\end{array}$ & & & & & $\begin{array}{l}< \\
0.001\end{array}$ \\
\hline$\square 18.5$ (underweight) & $322(7.0 \%)$ & $87(3.4 \%)$ & $208(10.6 \%)$ & $\begin{array}{l}27 \\
(32.5 \%)\end{array}$ & & $322(6.0 \%)$ & $63(3.6 \%)$ & $217(6.4 \%)$ & $43(18.9 \%)$ & \\
\hline 18.5-23.9 (normal weight) & $\begin{array}{l}2502 \\
(54.6 \%)\end{array}$ & $\begin{array}{l}1355 \\
(53.4 \%)\end{array}$ & $\begin{array}{l}1111 \\
(56.6 \%)\end{array}$ & $\begin{array}{l}36 \\
(43.4 \%)\end{array}$ & & $\begin{array}{l}2377 \\
(44.0 \%)\end{array}$ & $749(42.2 \%)$ & $\begin{array}{l}1511 \\
(44.5 \%)\end{array}$ & $44(19.3 \%)$ & \\
\hline 24.0-27.9 (over weight) & $\begin{array}{l}1315 \\
(28.7 \%)\end{array}$ & $842(33.2 \%)$ & $458(23.3 \%)$ & $\begin{array}{l}15 \\
(18.1 \%)\end{array}$ & & $\begin{array}{l}1867 \\
(34.6 \%)\end{array}$ & $690(38.9 \%)$ & $\begin{array}{l}1132 \\
(33.3 \%)\end{array}$ & 45 (19.7\%) & \\
\hline$\geqq 28$ (obesity) & $422(9.2 \%)$ & $247(9.7 \%)$ & $171(8.7 \%)$ & $4(4.8 \%)$ & & $812(15.0 \%)$ & $269(15.2 \%)$ & $523(15.4 \%)$ & $46(20.2 \%)$ & \\
\hline
\end{tabular}

${ }^{\text {a }}$ Data were weighted and expressed as number (\%) and compared with $\chi^{2}$ test 
${ }^{\mathrm{b}}$ Alcohol consumption referred to drinking such as beer, wine or liquor in the past year.

${ }^{\mathrm{c}}$ Smoking history was defined as the habit of smoking more than 100 cigarettes in a lifetime, both now and in the past.

${ }^{\mathrm{d}}$ Weight $(\mathrm{kg}) /$ height $(\mathrm{m})^{2}$

Table 3. Age-specific prevalence of frailty and pre-frailty in the general Chinese adult population aged 40 years or older in 2015

\begin{tabular}{|c|c|c|c|c|}
\hline & \multicolumn{3}{|c|}{ Prevalence $(\%)$ of frailty $(95 \% \mathrm{CI})$} & Prevalence $(\%)$ of pre-frailty $(95 \% \mathrm{CI})$ \\
\hline & men & women & total & women \\
\hline Overall & $1.8 \%(1.4,2.2)$ & $4.2 \%(3.7,4.8)$ & $3.1 \%(2.8,3.5)$ & $42.8 \%(41.4,44.2) 62.9 \%(61.6,64.2) 53.7 \%(52.7,54.6)$ \\
\hline \multicolumn{5}{|l|}{ Age (years) } \\
\hline $40-49$ & $1.5 \%(0.7,2.3)$ & $3.0 \%(2.0,4.1)$ & $2.4 \%(1.7,3.0)$ & $46.6 \%(43.2,49.9) 61.9 \%(59.0,64.8) 55.1 \%(52.9,57.4)$ \\
\hline $50-59$ & $2.1 \%(1.4,2.8)$ & $4.9 \%(3.9,5.9)$ & $3.6 \%(3.0,4.3)$ & $41.3 \%(38.8,43.8) 60.6 \%(58.3,62.8) 51.7 \%(50.0,53.4)$ \\
\hline $60-69$ & $1.5 \%(0.9,2.2)$ & $4.4 \%(3.4,5.4)$ & $3.1 \%(2.5,3.7)$ & $41.9 \%(39.3,44.5) 64.9 \%(62.6,67.2) 54.3 \%(52.5,56.1)$ \\
\hline $70-79$ & $1.7 \%(0.7,2.7)$ & $4.7 \%(3.1,6.2)$ & $3.3 \%(2.3,4.2)$ & $44.3 \%(40.5,48.1) 64.5 \%(61.0,68.0) 55.0 \%(52.4,57.6)$ \\
\hline$\geqq 80$ & $3.4 \%(0.9,6.0)$ & $1.4 \%(0.2,3.1)$ & $2.4 \%(0.9,3.9)$ & $38.9 \%(32.2,45.7) 66.2 \%(59.7,72.7) 52.7 \%(47.8,57.5)$ \\
\hline \multicolumn{5}{|l|}{ Education level } \\
\hline No formal education (illiterate) & $4.4 \%(2.7,6.0)$ & $6.0 \% \square 5.0,7.0)$ & $5.6 \%(4.8,6.5)$ & $55.1 \%(51.1,59.1) 67.2 \%(65.2,69.2) 64.6 \%(62.8,66.4)$ \\
\hline Elementary school & $1.6 \%(1.1,2.2)$ & $4.0 \%(3.1,4.8)$ & $2.8 \%(2.3,3.3)$ & $46.1 \%(44.0,48.2) 62.1 \%(60.1,64.2) 54.0 \%(52.6,55.5)$ \\
\hline Middle and high school & $1.2 \%(0.7,1.8)$ & $1.3 \%(0.6,2.0)$ & $1.3 \%(0.8,1.7)$ & $33.8 \%(31.5,36.0) 56.1 \%(53.1,59.0) 42.5 \%(40.6,44.3)$ \\
\hline College degree and higher & $0.0 \%$ & $0.0 \%$ & $0.0 \%$ & $46.2 \%(36.6,55.9) 56.4 \%(40.1,72.7) 49.0 \%(40.7,57.2)$ \\
\hline \multicolumn{5}{|l|}{ Marital status } \\
\hline Married and cohabitated & $1.6 \%(1.2,2.0)$ & $3.5 \%(2.9,4.0)$ & $2.6 \%(2.2,2.9)$ & $41.3 \%(39.7,42.8) 61.6 \%(60.1,63.0) 51.8 \%(50.7,52.9)$ \\
\hline Divorce, separated and Never marr & $1.5 \%(0.0,3.0)$ & $2.4 \%(0.6,4.2)$ & $2.0 \%(0.8,3.2)$ & $44.5 \%(38.5,50.6) 58.5 \%(52.8,64.2) 51.8 \%(47.6,56.0)$ \\
\hline Widowed & $4.2 \%(2.2,6.2)$ & $8.3 \%(6.5,10.1)$ & $7.1 \%(5.7,8.5)$ & $57.1 \%(52.1,62.1) 70.6 \%(67.6,73.6) 66.6 \%(64.0,69.2)$ \\
\hline \multicolumn{5}{|l|}{ Current residence } \\
\hline Urban & $1.8 \%(1.0,2.6)$ & $3.2 \%(2.2,4.2)$ & $2.6 \%(1.9,3.2)$ & $42.6 \%(39.5,45.6) 62.6 \%(59.8,65.3) 53.5 \%(51.4,55.6)$ \\
\hline Rural & $1.8 \%(1.4,2.3)$ & $4.5 \%(3.9,5.1)$ & $3.3 \%(2.9,3.7)$ & $42.9 \%(41.3,44.5) 62.9 \%(61.5,64.4) 37.3 \%(36.3,38.4)$ \\
\hline \multicolumn{5}{|l|}{ Alcohol consumption ${ }^{a}$} \\
\hline Drink more than once a month & $1.3 \%(0.8,1.8)$ & $4.7 \%(2.7,6.7)$ & $1.9 \%(1.4,2.4)$ & $38.8 \%(36.7,40.9) 60.6 \%(55.9,65.3) 42.5 \%(40.6,44.5)$ \\
\hline Drink but less than once a month & $0.2 \%(0.2,0.6)$ & $2.3 \%(0.7,3.8 \square$ & $1.1 \%(0.4,1.8)$ & $37.7 \%(33.2,42.1) 59.3 \%(54.1,64.4) 47.0 \%(43.5,50.4)$ \\
\hline None of these & $2.7 \%(2.0,3.4)$ & $4.3 \% \square 3.7,4.9 \square$ & $3.8 \%(3.4,4.3)$ & $48.0 \%(45.8,50.1) 63.4 \%(62.0,64.8) 58.7 \%(57.5,59.8)$ \\
\hline \multicolumn{5}{|l|}{ smoking history ${ }^{b}$} \\
\hline Current smoker & $1.7 \%(1.2,2.2)$ & $4.9 \%(2.4,7.5)$ & $2.0 \%(1.5,2.6)$ & $41.1 \%(39.1,43.0) 66.8 \%(61.3,72.3) 43.8 \%(41.9,45.6)$ \\
\hline Former smoker & $2.2 \%(1.4,3.0)$ & $7.9 \%(3.6,12.2)$ & $2.8 \%(1.9,3.7)$ & $44.9 \%(42.1,47.7) 67.1 \%(59.6,74.7) 47.4 \%(44.7,50.1)$ \\
\hline Never smoker & $1.6 \%(0.8,2.4)$ & $4.1 \%(3.5,4.6)$ & $3.7 \%(3.2,4.1)$ & $44.4 \%(41.3,47.5) 62.6 \%(61.2,63.9) 59.6 \%(58.3,60.8)$ \\
\hline \multicolumn{5}{|l|}{ Body mass index $\left(\mathrm{kg} / \mathrm{m}^{2}\right)^{\mathrm{c}}$} \\
\hline ¿18.5 (underweight) & $8.4 \%(5.3,11.4)$ & $13.4 \%(9.6,17.1)$ & $10.9 \%(8.5,13.3$ & $64.6 \%(59.3,69.8) 67.4 \%(62.2,72.5) 66.0 \%(62.3,69.7)$ \\
\hline 18.5-23.9 (normal weight) & $1.4 \%(1.0,1.9)$ & $1.9 \%(1.3,2.4)$ & $1.6 \%(1.3,2.0)$ & $44.4 \%(42.5,46.4) 63.6 \%(61.6,65.5) 53.7 \%(52.3,55.1)$ \\
\hline 24.0-27.9 (over weight) & $1.1 \%(0.6,1.7)$ & $2.4 \%(1.7,3.1)$ & $1.9 \%(1.4,2.4)$ & $34.8 \%(32.3,37.4) 60.6 \%(58.4,62.9) 50.0 \%(48.2,51.7)$ \\
\hline$\geqq 28$ (obesity) & $0.9 \%(0.0,1.9)$ & $5.7 \%(4.1,7.3)$ & $4.1 \%(3.0,5.2)$ & $40.5 \%(35.8,45.2) 64.4 \%(61.1,67.7) 56.2 \%(53.5,59.0)$ \\
\hline
\end{tabular}

Abbreviations: CI, confidence interval;

${ }^{\text {a }}$ Alcohol consumption referred to drinking such as beer, wine or liquor in the past year.

${ }^{\mathrm{b}}$ Smoking history was defined as the habit of smoking more than 100 cigarettes in a lifetime, both now and in the past.

${ }^{\mathrm{c}}$ Weight $(\mathrm{kg}) /$ height $(\mathrm{m})^{2}$

Table 4. Blood-based bioassays and physical measurements for frail status ${ }^{a}$ 


\begin{tabular}{|c|c|c|c|c|c|}
\hline Variables (Unit) & $\begin{array}{l}\text { Total } \\
(\mathrm{n}=9985)\end{array}$ & $\begin{array}{l}\text { Not frail } \\
(\mathrm{n}=4316)\end{array}$ & $\begin{array}{l}\text { Pre-frail } \\
(n=5358)\end{array}$ & $\begin{array}{l}\text { Frail } \\
(n=311)\end{array}$ & $P$-value Missing data \\
\hline Systolic blood pressure (mmHg) & $128.8(20.3)$ & $127.9(19.1)$ & $129.2(21.0)$ & $133.8(23.6)$ & $<0.001108$ \\
\hline Diastolic blood pressure $(\mathrm{mmHg})$ & $75.3(11.9)$ & $76.3(11.9)$ & $74.7(11.8)$ & $73.7(11.8)$ & $<0.00185$ \\
\hline Pulse (beat per minute) & $74.1(10.8)$ & $73.7(10.4)$ & $74.2(10.9)$ & $76.6(12.1)$ & $<0.00185$ \\
\hline Peak expiratory flow (L/min) & $283.6(116.5)$ & $321.2(116.6)$ & $258.4(107.3)$ & $188.5(95.5)$ & $<0.001175$ \\
\hline Waist circumference (cm) & $85.0(13.4)$ & $85.3(13.3)$ & $84.9(13.5)$ & $83.6(12.6)$ & 0.042 \\
\hline Body mass index $\left(\mathrm{kg} / \mathrm{m}^{2}\right)$ & $23.8(5.0)$ & $24.0(4.1)$ & $23.8(5.7)$ & $21.9(4.0)$ & $<0.00145$ \\
\hline Night sleep time (hours) & $6.4(2.0)$ & $6.5(1.8)$ & $6.3(2.1)$ & $6.2(2.4)$ & $<0.001335$ \\
\hline White blood cell $\left(1000 / \mathrm{mm}^{3}\right)$ & $6.0(1.8)$ & $6.0(1.9)$ & $5.9(1.8)$ & $6.0(1.9)$ & 1646 \\
\hline Hemoglobin (g/dL) & $13.7(2.0)$ & $14.0(2.0)$ & $13.4(1.8)$ & $12.9(2.1)$ & $<0.0011646$ \\
\hline Hematocrit (\%) & $41.4(5.7)$ & $42.3(5.9)$ & $40.7(5.3)$ & $39.4(6.1)$ & $<0.0011646$ \\
\hline Mean corpuscular volume (fL) & $91.5(7.8)$ & $91.5(7.5)$ & $91.5(8.0)$ & $91.6(8.2)$ & 0.895 \\
\hline Platelets $\left(10^{9} / \mathrm{L}\right)$ & $203.5(76.5)$ & $204.4(79.5)$ & $202.7(74.1)$ & $204.9(74.6)$ & 0.571 \\
\hline Triglycerides (mg/dL) & $141.3(89.3)$ & $143.4(93.6)$ & $140.0(86.5)$ & $133.0(70.3)$ & 0.077 \\
\hline Creatinine (mg/dL) & $0.8(0.3)$ & $0.8(0.3)$ & $0.8(0.3)$ & $0.8(0.4)$ & $<0.0011590$ \\
\hline Blood urea nitrogen (mg/dL) & $15.7(4.8)$ & $15.6(4.6)$ & $15.7(4.9)$ & $16.4(5.4)$ & 0.0221588 \\
\hline HDL cholesterol (mg/dL) & $51.7(11.9)$ & $51.6(11.7)$ & $51.6(11.9)$ & $52.6(12.9)$ & 0.433 \\
\hline LDL cholesterol (mg/dL) & $102.8(28.8)$ & $103.2(28.0)$ & $102.4(29.4)$ & $104.8(29.5)$ & 0.281 \\
\hline Total Cholesterol (mg/dL) & $184.8(36.6)$ & $185.2(35.9)$ & $184.3(37.1)$ & $186.9(37.0)$ & 0.386 \\
\hline Glucose (mg/dL) & $103.2(34.9)$ & $101.5(30.3)$ & $104.3(37.1)$ & $106.8(52.3)$ & $<0.0011570$ \\
\hline Uric acid (mg/dL) & $4.9(1.4)$ & $5.1(1.4)$ & $4.8(1.4)$ & $5.0(1.7)$ & $<0.0011570$ \\
\hline Cystatin C (mg/L) & $0.9(0.3)$ & $0.8(0.2)$ & $0.9(0.3)$ & $1.0(0.5)$ & $<0.0011593$ \\
\hline C-reactive protein $(\mathrm{mg} / \mathrm{L})$ & $2.8(6.2)$ & $2.5(5.5)$ & $3.0(6.4)$ & $4.7(11.6)$ & $<0.0011590$ \\
\hline HbA1C (\%) & $6.0(1.0)$ & $5.9(0.8)$ & $6.1(1.1)$ & $6.2(1.3)$ & $<0.0011554$ \\
\hline
\end{tabular}

Abbreviation: HbA1C, glycated hemoglobin; HDL, high-density lipoprotein; LDL, low-density lipoprotein; SD, standard deviation.

${ }^{\text {a }}$ Data were weighted and expressed as mean (SD) and compared with ANOVA.

Table 5. Multiple-adjusted ORs for frailty and pre-frailty related factors for Chinese adults aged 40 and over 


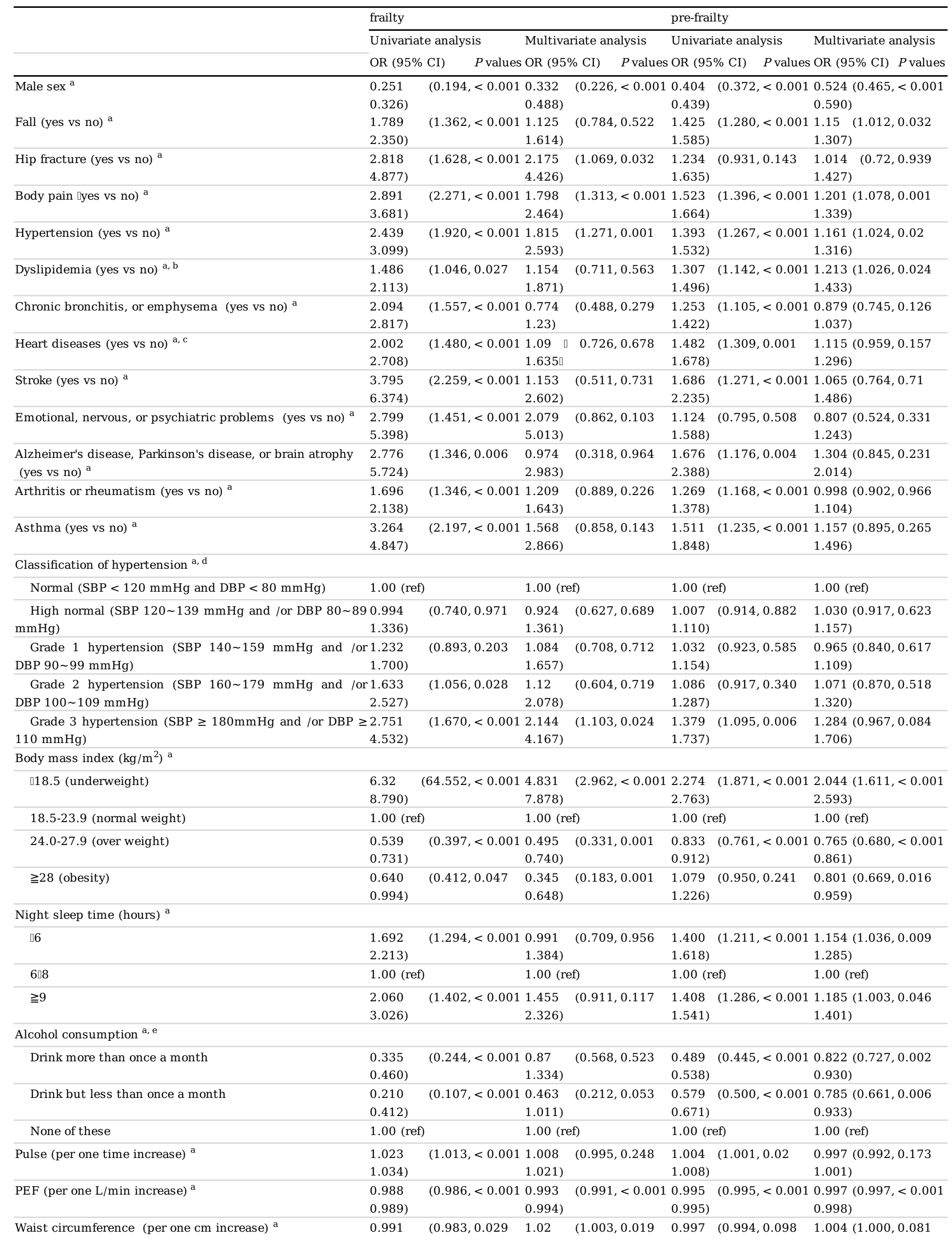




\begin{tabular}{|c|c|c|c|c|c|c|}
\hline & 0.999) & 1.037) & & $1.000)$ & & 1.009) \\
\hline \multirow[t]{2}{*}{ Cystatin $\mathrm{C}$ (per one $\mathrm{mg} / \mathrm{L}$ increase) ${ }^{a}$} & 6.855 & $(4.631,<0.0014 .504$ & $(3.012,<0.001$ & 11.001 & $(0.990,0.892$ & $2.415(1.866,<0.001$ \\
\hline & 10.148) & $6.735)$ & & $1.012)$ & & $3.126)$ \\
\hline \multirow[t]{2}{*}{ HbA1C (per one percentage increase) ${ }^{a}$} & 1.247 & $(1.126,<0.0011 .226$ & $(1.072,0.003$ & 1.142 & $(1.091,<0.001$ & $1.11 \quad(1.051,<0.001$ \\
\hline & 1.381) & $1.402)$ & & 1.196) & & 1.172) \\
\hline
\end{tabular}

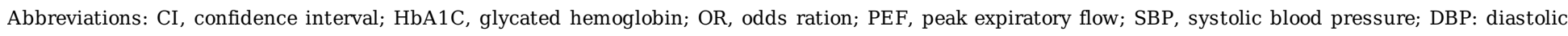
blood pressure;

${ }^{\text {a }}$ Variables introduced in Multivariate analysis.

${ }^{\mathrm{b}}$ Dyslipidemia included elevated total cholesterol, triglycerides, and low-density lipoprotein, or low high-density lipoprotein levels.

${ }^{\mathrm{c}}$ Heart diseases included coronary heart disease, heart attack, congestive heart failure, angina or other heart problems

${ }^{\mathrm{d}}$ The following was the classification and definition of blood pressure level, when SBP and DBP are of different grades, the higher grade shall prevail.

${ }^{\mathrm{e}}$ Alcohol consumption referred to drinking such as beer, wine or liquor in the past year. 